\title{
Investment Strategies of Different Holding Periods: Evidence from Stock Markets of Hong Kong, Korea, Shanghai, and Taiwan
}

\author{
Massoud Moslehpour \\ Dept. of Business Administration, Asia University \\ 500, Lioufeng Rd., Wufeng, Taichung 41354, Taiwan \\ Tel: +886-423-323-456 (Ext.1962) E-mail: writetodrm@gmail.com \\ Munkh-Ulzii Batmunkh (Corresponding author) \\ Dept. of Business Administration, Asia University \\ 500, Lioufeng Rd., Wufeng, Taichung 41354, Taiwan \\ Tel: +886-423-323-456 E-mail: ulzii03@gmail.com
}

Received: November 1, 2013 Accepted: November 15, 2013

doi:10.5296/ber.v3i2.4491 URL: http://dx.doi.org/10.5296/ber.v3i2.4491

\begin{abstract}
Although there is abundant research focusing on estimating the level of returns on stock market, there is a lack of studies examining the comparison of stock return movements for short-term and long-term investment in the Asian stock market. The present study examines return on investment of different holding periods among selected stock markets in Asia. Based on the trading performance of key indices and market capitalization value, Korean Stock Exchange (KRE), Shanghai Stock Exchange (SSE), Hong Kong Stock Exchange (HKSE), and Taiwan Stock Exchange (TWSE) were selected for this study. In assessing the comparative output of the case stock markets, this study used ANOVA and post-hoc analysis to process time series data of daily, monthly, quarterly, semiannually and annually return of investments of indices of the case stock markets. The results of this study showed that there are significant differences in return on investment among the case stock markets in the given holding periods. While a country might have a higher return in short-term investment, it may not necessarily be suitable for long-term investment as evidenced by their performance from 2001 to 2012.
\end{abstract}


Keywords: Return on Investment, Holding Periods, Short-Term and Long-Term Investment, HSI, KOSPI, SSECI, TAIEX

\section{Introduction}

Investment in stock markets has gained unprecedented popularity in financial markets around the world. Recently the increasing diversity of financial instruments has broadened the dimension of global investment opportunity to both individual and institutional investors. Overall competitive pressure has been increased on many stock exchanges due to a range of significant changes in the industrial environment. The intensive globalization activity brings stock markets from home-based state to the international arena, where severe competition for surviving in the financial markets held among investors (Michael, 2009; Sulloway, 2009).

Amid this harsh competition, it is not so easy to make profit from an investment. There are many economic and social barriers awaiting the investment to be crashed. When macroeconomic indicators, such as inflation rate and interest rate, move up or down they will simultaneously trigger uncertainty among the investment decision. Once uncertainty happens, investors start to sell stocks in order to protect their asset value from devaluation. In the grand scale, this movement induces volatility into stock markets, which finally cause the value of shares sink down (Koshnazarov, 2010).

In contrast, during the periods of macroeconomic stability the value of shares keep growing positively which sends a message to the investors to keep their assets, and even invest more in buying new shares. Once a positive sign of value of shares appears among investors, demand for new shares spikes in stock markets, which pulls the price of the shares up. But, this suitable period of time does not last forever and difficult times for equity values could be the next movement of the stock market (Araujo, 2009; Chow, Kim, \& Sun, 2007).

Therefore, studies in finance overwhelmingly agree that the volatility in stock markets is the direct reaction to the investment behavior of fund managers. Sometimes financial markets crash without potential swing in economic fundamentals. Studies conclude that this scenario appears to be as a common case of investment misbehaving or irrational investment behavior, which is driven by emotion-greed in the bubbles and fear in the crashes (Climent \& Meneu, 2003; Chiang \& Zheng, 2010).

Although investment behavior is the key factor in driving stock prices, however, the stock market performance (measured by market capitalization), trading volume and market return on investment are also crucial factors for investors. In order to make profit, investors analyze stock market performance, plan their strategy, and finally put their strategy into action. This process in whole is called investment behavior (Abdulkadir \& Green, 2002; Indrawati, 2002). Thus, the main purpose of this paper is to compare return on investments among different stock markets, in Asia in terms of different timing periods.

The capital markets in US and other largest economies might have already been matured. Therefore, investors now tend to invest into the emerging capital markets of Asia, preferably South Korea, Taiwan, Hong Kong, and Shanghai, to raise value of their assets. Since 1970s, 
these countries started to exhibit a notable economic growth, and shortly were named as the tiger economies in the world. The upcoming body of this study focuses more on the stock markets of mentioned countries, and their performances (Pontines \& Siregar, 2009; Singh, Kumar, \& Pandey, 2010).

\subsection{Research Problem}

The main problem of investors of all times has been the issue of how to do an investment with low risk and high margin. Even experienced investors do betting blindly as if they were gambling. According to the previous studies, investment returns may vary in holding-periods, such as short-term and long-term investment. Thus, studies denote that the differences in holding periods in investment appear to be as one of the essential factors for investment strategy (Rigobon, 2003; Zhou, Wu, \& Yang, 2011; Singh et al., 2010).

Global equity markets and regional markets are often correlated with one another, especially in times of economic recession with a prominent contagion and spillover effects. Even in relatively stable periods, co-moving trending behavior might be presented across equity markets. Studies on interrelations of equity markets could provide a useful insight for the international investors who look forward for diversified opportunities. Since co-movements are common among stock markets, the cross-market gains and losses are prevalent. Nevertheless, emerging markets with explosive growth rates, such as those in Asia and Pacific region, have recently attracted market players who seek to diversify their portfolio (Tan, Chiang, Mason, \& Nelling, 2008).

Emerging economies as well as tiger economies are nations with social and economic activity in the process of rapid growth and industrialization. This process is usually accompanied by an increase in foreign and domestic investments and life quality. Thus, stock markets of South Korea, Taiwan, Hong Kong, and Shanghai exhibit characteristics both of emerging and tiger markets that predominantly attract investors 'interest. However, studies state that one of the key features of emerging markets is that they frequently tend to display upward and downward movements in stock prices in either of short-term and long term periods. These characteristics of stock market boost momentum and market swings which in turn add to the market volatility (Liu, Pan, \& Shieh, 1998; Pontines \& Siregar, 2009).

Individual investors speculate in short-term and mid-term strategies. However, institutional investors head for wealth maximization in primary and secondary markets by implementing long-term investment and other strategies, such as merging and acquisition, as well as IPOs. Institutional investors rely mostly on long-term value from an investment rather than speculating in short-term. The key point of long-term investment strategy is not only increasing the value of capital asset, but also investors can receive income from shares, which is known as a dividend (In, Kim, \& Yoon, 2002; Pontines \& Siregar, 2009).

With the foregoing discussion we tried to construct a firm perception of how holding periods are essential for the decision making pattern of investors, which have recently appeared as one of the front line issues of latter studies. Do different holding periods impact the investment returns in emerging stock markets? This is the main question of this study that needs to be 
answered. Thus, present study implements a comparison among investment returns of emerging stock markets for different holding periods. As for the case stock markets, we select Shanghai Stock Exchange (hereinafter referred to as SSE), Hong Kong Stock Exchange (hereinafter referred to as HKSE), Taiwan Stock Exchange (hereinafter referred to as TWSE), and Korean Stock Exchange (hereinafter referred to as KRE).

\section{Related Research and Hypothesis Development}

The main purpose of this paper is to give a reasonable answer to the research question: Are there any significant differences among investment time periods for investment returns in TWSE, KRE, SSE, and HKSE? If yes, to what extent are these differences exhibited among the markets? In order to translate the question into theoretical framework we review the following body of literature.

Recently investors are increasingly seeking for opportunities to minimize the portfolio risk for an investment return in a given period of time. It is a well established fact that the lower the correlations among international equity markets the lesser the investment risk. However, the recent trend of development of emerging stock markets increased the correlation among equity markets. Therefore, high volatility in returns still exists among developed and emerging equity markets in terms of holding periods (Dimson, Marsh, \& Staunton, 2002; Li, Sarkar, \& Wang, 2003; Goetzmann, Li, \& Rouwenhorst, 2005).

Numbers of studies reveal differences in returns among the Asian stock markets impacted by western markets, in both short-term and long-term intervals (Cha \& Cheung, 1998; De Roon, Nijman, \& Werker, 2001; Syriopoulos, 2004). However, so far, there is no study to investigate relationships among the case stock markets of this study.

Mukherjee and Bose (2008) found that recent returns on Indian stock market were severely influenced by US and other Asian markets including Japan. More importantly, outcomes of their study suggest that Indian stock market returns impact on the stock returns of major markets of Asia. Moreover, studies demonstrate that US capital market often exhibit a significant impact on Asian equity markets in long-term. As well, a notable correlation among markets of the same region is explained by the degree of restrictions on foreign investment or certain market characteristics, such as market returns in different holding periods and market liquidity (Elyasiani, Perera, \& Puri, 1998; Lin, 2008).

Hsiao, Hsiao, and Yamashita (2003) found a significant unidirectional causality from the US market towards stock market returns of Japan and Korea, but not to China and Taiwan. They also found that the Chinese stock market, based on the data of Shanghai Composite price index, is not significantly correlated with rest of the Asian markets.

Janakiramanan and Lamba (1998) found that the stock markets of US impact the majority of Asian markets except for the relatively segmented market of Indonesia. They also revealed that markets that are located geographically close, such as Australia-New Zealand and Singapore-Malaysia affect to each other.

Singh, Kumar and Pandey (2010) examine the stock returns volatility spillover effects across 
fifteen stock markets of North America, Europe and Asia. Their research sample for the Asian stock markets includes China and Indonesia; and the composite stock indices data are used for both markets. In assessing the investment returns spillover effects, they employed vector autoregression model, which is used to capture the linear interdependencies among multiple time series data. Results of their study suggest that information flow within stock markets plays main role in investment returns. For example, a market that opens earlier generally tends to have a greater effect on those that open later. Especially, this phenomenon is often displayed between the equity markets of Japan, Singapore and Hong Kong.

Climent and Meneu (2003) assessed the impacts of the Asian capital market crisis in 1997, on implication of Southeast Asian markets that include Indonesia, Philippines and Thailand, and US. Results of their study state that the US equity market affects all the Asian stock markets except Korea. Moreover, findings of this study also suggest that Asian stock markets with the close geographical and economical zone demonstrate significant correlations in their investment returns in short-term and long-term time horizons.

Furthermore, In et al. (2001) examined causality between HKSE, Thailand stock market, and KRE. They found that Thailand stock market exhibits greater market interdependence, while HKSE appears as the potential generator of volatility through other Asian stock markets. Pontines and Siregar (2009) examined correlation of market returns in different holding periods among eight east Asian stock markets, around the time of the Asian financial recession. They found significant evidence of increased correlations among market returns on both of short-term and long-term investment in the post-crisis period, starting especially with declining in HKSE.

Lee (2009) measured return volatility spillover effects in short-term and long-term investments among six east Asian stock markets including India. Results found significant spillover effects among five countries that are geographically close, and as markets as close to each other the effects were greater. Chuang, Lu, and Tswei (2007) did same study among six Asian stock markets including Thailand. They found high interdependencies on investment returns in various time horizons, and the Japanese stock market appears to be a potential volatility transmitter to other east Asian markets. For the same purpose Singh et al. (2010) used a GARCH model. They found that the volatility of a particular market return is mostly affected by one that opens earlier. According to their results the correlation among the Asian markets was strong.

\subsection{Hypothesis Development}

Reviewing the theoretical background, we noticed several important aspects for developing theoretical framework. First, it is obvious that examining correlation of investment returns within same holding period, or among the same market, as well as the markets that are not considered to be related to each other, is not good idea. The reason is that correlations between market returns are more profound among markets that belong to the same geographical and economical zone. Moreover, returns of equity markets vary according to the holding periods. Second, previous studies tested the impacts and relationships among stock markets of Asia and US, but did not target solely on the Asian markets. Therefore, in order to generate rather new 
outcomes, as shown in the Figure 1, we develop the following theoretical framework and hypothesis.

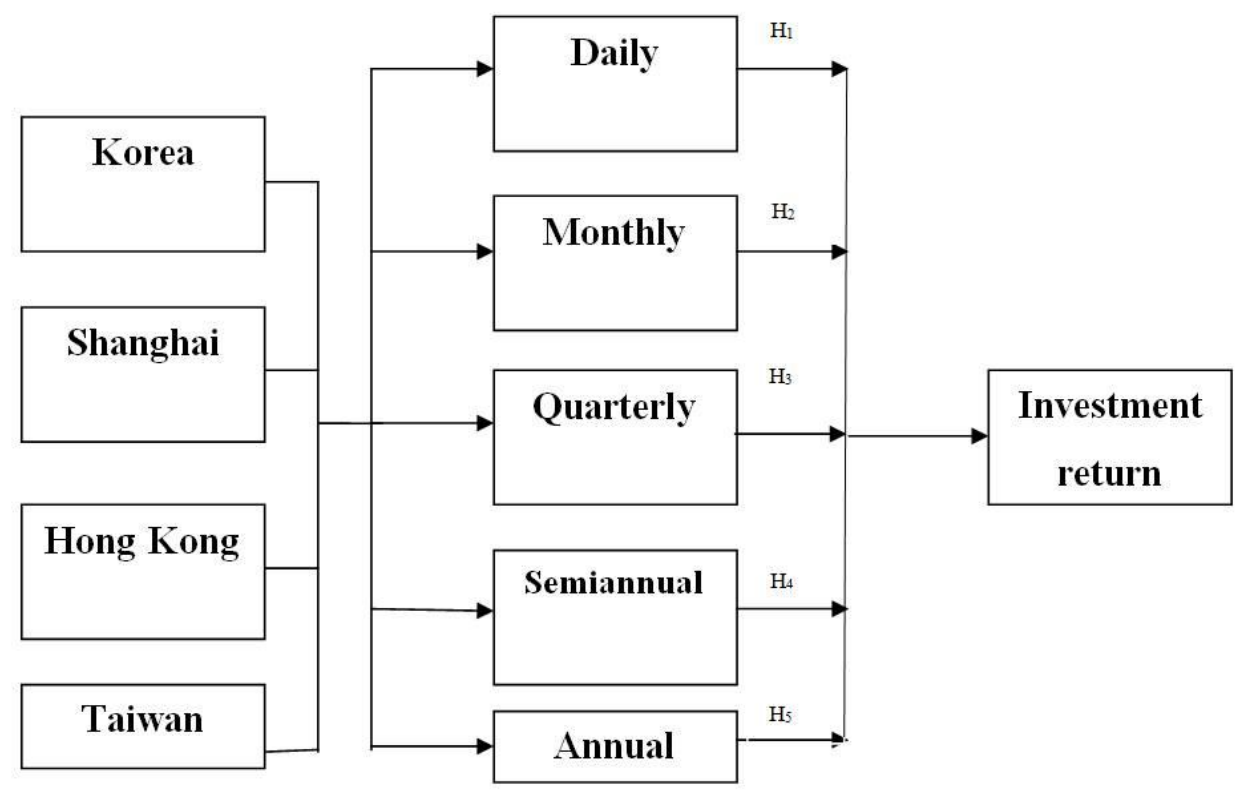

Figure 1. Research framework

Basing on theoretical foundation, the present study develops the following hypotheses:

$\mathbf{H}_{1}$ : There are significant differences among TWSE, HKSE, SSE, and KRE in their daily investment returns for the period of 2001-2011.

$\mathbf{H}_{2}$ : There are significant differences among TWSE, HKSE, SSE, and KRE in their monthly investment returns for the period of 2001-2011.

$\mathbf{H}_{3}$ : There are significant differences among TWSE, HKSE, SSE, and KRE in their quarterly investment returns for the period of 2001-2011.

$\mathbf{H}_{4}$ : There are significant differences among TWSE, HKSE, SSE, and KRE in their semiannually investment returns for the period of 2001-2011.

H5: There are significant differences among TWSE, HKSE, SSE, and KRE in their annually investment returns for the period of 2001-2011.

\section{Research Methodology}

\subsection{Data}

This study uses time series data of index prices of HSI, KOSPI, SSECI, and TAIEX; covering periods from January 2001 to April 2012. The time period of chosen data constitutes the availability and limitation of data source. In order to capture returns in different time horizons we divided data into time scales of day, month, quarter, semiannual and annual base. The data for this study was collected from the data source Thomson Reuters Datastream (2013). 


\subsection{Methodology}

To test the hypotheses of this study we employed analysis of variance (ANOVA). ANOVA is used to test significance of differences among the means. Furthermore, in order to find the detailed differences among the subgroups, that could be otherwise undetected; we adopted post-hoc analysis. Post hoc test is designed for situations in which the researcher has already obtained a significant omnibus F-test with a factor that consists of three or more means and additional exploration of the differences among means is needed to provide specific information on which means are significantly different from each other (Hung, Lu, \& Lee, 2010).

Also the descriptive statistics display the characteristics, functions, relationship and patterns of the research phenomena. It also explains and validates findings. For this study, the p-value is less than or equal to 5\% to indicate statistical significance and to control for type I and type II error. (Rigobon, 2003).

\subsection{Case Stock Markets}

\subsubsection{Twse}

The TWSE is operated by the Taiwan Stock Exchange Corporation (TWSEC), which is a financial institution that located in Taipei 101, in Taipei, Taiwan. The TWSEC was established in 1961 and began operating as a stock exchange on 9 February 1962. It is regulated by the Financial Supervisory Commission of Taiwan. As of 31 December 2010, the TWSE had 758 listed companies with a combined market capitalization of USD821,083 million.

Taiwan Capitalization Weighted Stock Index (TAIEX) is a stock market index for companies traded on the TWSE. TAIEX covers all of the listed stocks excluding preferred stocks, full-delivery stocks and newly listed stocks, which are listed for less than one calendar month. It was first published in 1967 by TWSE with 1966 being the base year with a value of 100 (Taiwan Stock Exchange, 2013).

\subsubsection{KRE}

KRE is the sole securities exchange operator in South Korea. It is headquartered in Busan, and has an office for cash markets and market oversight in Seoul. The KRE was created through the integration of Korea Stock Exchange, Korea Futures Exchange and KOSDAQ Stock Market under the Korea Stock \& Futures Exchange Act. The securities and derivatives markets of former exchanges are now business divisions of KRE: the Stock Market Division, KOSDAQ Market Division and Derivatives Market Division. As of October 2012, KE had 1,796 listed companies with a combined market capitalization of USD1.1 trillion. The Korea Composite Stock Price Index (KOSPI) is the index of all common stocks traded on the KRE. It's the representative stock market index of South Korea. KOSPI was introduced in 1983 with the base value of 100 as of January 4, 1980. It's calculated based on market capitalization (Korean Stock Exchange, 2013). 


\subsubsection{SSE}

The SSE is a stock exchange that is based in the city of Shanghai, China. It is one of the two stock exchanges operating independently in the People's Republic of China, the other is the Shenzhen Stock Exchange. SSE is the one of the six largest stock exchanges in the world by market capitalization at USD2.3 trillion as of Dec 2011. Unlike the HKSE, the SSE is still not entirely open to foreign investors due to tight capital account controls exercised by the Chinese mainland authorities. The current exchange was re-established on November 26, 1990 and was in operation on December 19 of the same year. It is a non-profit organization directly administered by the China Securities Regulatory Commission.

The SSE Composite Index (SSECI) is the most commonly used indicator to reflect SSE's market performance. Constituents for the SSECI are all listed stocks including at the SSE. The base day for the SSECI is December 19, 1990. The base period is the total market capitalization of all stocks of that day. The base value is 100. The index was launched on July 15, 1991 (Shanghai Stock Exchange, 2013).

\subsubsection{HKSE}

The HKSE is a stock exchange located in Hong Kong. It is Asia's second largest stock exchange in terms of market capitalization behind the Tokyo Stock Exchange, and the fifth largest in the world. As of 30 November 2011, the HKSE had 1,477 listed companies with a combined market capitalization of USD2191.6 trillion.

The Hang Seng Index (HSI) is a free float-adjusted market capitalization-weighted stock market index of HKSE. It is used to record and monitor daily changes of the largest companies of the HKSE and is the main indicator of the overall market performance in Hong Kong. These 48 constituent companies represent about $60 \%$ of capitalization of the HKSE. HSI was started on November 24, 1969, and is currently compiled and maintained by Hang Seng Indices Company Limited (Hong Kong Stock Exchange, 2013).

\section{Empirical Findings}

Under the assumption of five hypotheses in this study, we analyze the time series data of indices HSI, KOSPI, SSECI, and TAIEX to find out degree of correlation in different holding periods. The data is divided into five timing scales such as daily, monthly, quarterly, semiannually, and annually, and analyzed by ANOVA modeling techniques and post-hoc test.

\subsection{Descriptive Statistics}

Descriptive statistics is the discipline of quantitatively describing the main features of data. Descriptive statistics are distinguished from inferential statistics, in that it aims to summarize a data, rather than use the data to learn about the population. This generally means that descriptive statistics, unlike inferential statistics, is not developed on the basis of probability theory. Even when a data analysis draws its main conclusions using inferential statistics, descriptive statistics are generally also presented. 
Table 1. Descriptive statistics of the four case stock markets

\begin{tabular}{|c|c|c|c|c|c|c|c|c|c|}
\hline \multirow[t]{2}{*}{ Periods } & \multirow[t]{2}{*}{ Code } & \multirow[b]{2}{*}{$\mathrm{N}$} & \multirow[b]{2}{*}{ Mean } & \multirow{2}{*}{$\begin{array}{c}\text { Std. } \\
\text { Deviation }\end{array}$} & \multirow{2}{*}{$\begin{array}{l}\text { Std. } \\
\text { Error }\end{array}$} & \multicolumn{2}{|c|}{$\begin{array}{l}\text { 95\% Confidence Interval for } \\
\text { Mean }\end{array}$} & \multirow[b]{2}{*}{ Minimum } & \multirow[b]{2}{*}{ Maximum } \\
\hline & & & & & & Lower Bound & Upper Bound & & \\
\hline \multirow{5}{*}{ Daily } & KRE & 2482 & .00052 & .015984 & .000321 & -.00011 & .00115 & -.106 & .119 \\
\hline & SSE & 2482 & .00571 & .083138 & .001669 & .00244 & .00899 & -.250 & .350 \\
\hline & HKSE & 2482 & .02073 & .121428 & .002437 & .01595 & .02551 & -.515 & .637 \\
\hline & TWSE & 2482 & .04694 & .201066 & .004036 & .03902 & .05485 & -.525 & .788 \\
\hline & Total & 9928 & \begin{tabular}{|l|}
.01847 \\
\end{tabular} & .126116 & .001266 & .01599 & .02095 & -.525 & .788 \\
\hline \multirow{5}{*}{ Monthly } & KRE & 2482 & .00028 & .017037 & .000342 & -.00039 & .00095 & -.088 & .095 \\
\hline & SSE & 2482 & .00612 & .066711 & .001339 & .00349 & .00874 & -.410 & .322 \\
\hline & HKSe & 2482 & .02081 & .134813 & .002706 & .01550 & .02611 & -.413 & .612 \\
\hline & TWSE & 2482 & .15736 & .248274 & .004983 & .14759 & .16713 & -.535 & .828 \\
\hline & Total & 9928 & .04614 & .159098 & .001597 & .04301 & .04927 & -.535 & .828 \\
\hline \multirow{5}{*}{ Quarterly } & KRE & 2482 & .00052 & .015984 & .000321 & -.00011 & .00115 & -.106 & .119 \\
\hline & SSE & 2482 & .00456 & .066194 & .001329 & .00196 & .00717 & -.264 & .261 \\
\hline & HKSE & 2482 & .07817 & .198077 & .003976 & .07038 & .08597 & -.488 & .909 \\
\hline & TWSE & 2482 & -.33306 & .280194 & .005624 & -.34409 & -.32203 & -.838 & .392 \\
\hline & Total & 9928 & -.06245 & .236545 & .002374 & -.06710 & -.05780 & -.838 & .909 \\
\hline \multirow{5}{*}{$\begin{array}{c}\text { Semi } \\
\text { annually }\end{array}$} & KRE & 2482 & .00022 & .014446 & .000290 & -.00035 & .00079 & -.088 & .067 \\
\hline & SSE & 2482 & .03563 & .124644 & .002502 & .03073 & .04054 & -.401 & .493 \\
\hline & HKSE & 2482 & .05435 & .298261 & .005987 & .04261 & .06609 & -.533 & 1.125 \\
\hline & TWSE & 2482 & -.85676 & .052857 & .001061 & -.85884 & -.85468 & -.942 & -.664 \\
\hline & Total & 9928 & -.19164 & .417995 & .004195 & -.19986 & -.18342 & -.942 & 1.125 \\
\hline \multirow{5}{*}{ Annually } & KRE & 2482 & \begin{tabular}{|l|}
.01059 \\
\end{tabular} & .066847 & .001342 & .00796 & .01322 & -.375 & .240 \\
\hline & SSE & 2482 & .02193 & .169393 & .003400 & .01526 & .02860 & -.394 & .646 \\
\hline & HKSE & 2482 & .04513 & .186937 & .003752 & .03777 & .05248 & -.580 & .803 \\
\hline & TWSE & 2482 & 1.67257 & .714040 & .014332 & 1.64447 & 1.70068 & .183 & 4.406 \\
\hline & Total & 9928 & .43755 & .808131 & .008111 & .42166 & .45345 & -.580 & 4.406 \\
\hline
\end{tabular}

\subsection{ANOVA Analysis}

In statistics, ANOVA is a statistical model, in which the observed variance in a particular variable is partitioned into components attributable to different sources of variation. In its simplest form, ANOVA provides a statistical test of whether or not the means of several groups are all equal. For this reason, ANOVA is useful in comparison of more than two means. According to the results generated from ANOVA analysis shown in the Table 2, all the proposed hypotheses of this study are supported.

Table 2. ANOVA testing of the four stock markets

\begin{tabular}{|c|l|c|c|c|c|c|}
\hline & & Sum of Squares & df & Mean Square & F & Sig. \\
\hline \multirow{3}{*}{ Daily } & Between Groups & 3.228 & 3 & 1.076 & 69.033 & .000 \\
\cline { 2 - 8 } & Within Groups & 154.664 & 9924 & .016 & & \\
\cline { 2 - 8 } & Total & 157.892 & 9927 & & & \\
\hline
\end{tabular}




\begin{tabular}{|c|l|c|c|c|c|c|}
\hline \multirow{4}{*}{ Monthly } & Between Groups & 41.491 & 3 & 13.830 & 654.269 & .000 \\
\cline { 2 - 8 } & Within Groups & 209.781 & 9924 & .021 & & \\
\hline & Total & 251.273 & 9927 & & & \\
\hline \multirow{4}{*}{$\begin{array}{c}\text { Suarterly } \\
\text { annually }\end{array}$} & Between Groups & 251.824 & 3 & 83.941 & $2.744 \mathrm{E} 3$ & .000 \\
\cline { 2 - 8 } & Within Groups & 303.625 & 9924 & .031 & & \\
\cline { 2 - 8 } & Total & 555.449 & 9927 & & & \\
\hline & Wetween Groups & 1467.736 & 3 & 489.245 & $1.820 \mathrm{E} 4$ & .000 \\
\hline & Within Groups & 266.704 & 9924 & .027 & & \\
\hline \multirow{3}{*}{ Annually } & Total & 1734.440 & 9927 & & & \\
\cline { 2 - 8 } & Wetween Groups & 5049.166 & 3 & 1683.055 & $1.165 \mathrm{E} 4$ & .000 \\
\cline { 2 - 8 } & Wothin Groups & 1433.922 & 9924 & .144 & & \\
\hline
\end{tabular}

\subsection{Post-hoc Analysis}

In the design and analysis of experiments, post-hoc analysis consists of looking at the data-after the experiment has concluded-for patterns that were not specified $a$ priori. It is sometimes called by critics data dredging to evoke the sense that the more one looks the more likely something will be found. More subtly, each time a pattern in the data is considered, a statistical test is effectively performed. This greatly inflates the total number of statistical tests and necessitates the use of multiple testing procedures to compensate.

However, this is difficult to do precisely and in fact most results of post-hoc analyses are reported as they are with unadjusted p-values. These p-values must be interpreted in light of the fact that they are a small and selected subset of a potentially large group of p-values. Results of post-hoc analysis should be explicitly labeled in studies to avoid misleading of audience.

Table 3. Post hoc analysis for daily stock index

\begin{tabular}{|c|c|c|c|c|c|c|c|}
\hline \multirow[b]{2}{*}{ Dependent Variable } & \multirow[b]{2}{*}{ (I) country } & \multirow[b]{2}{*}{$(\mathrm{J})$ country } & \multirow{2}{*}{$\begin{array}{c}\text { Mean Difference } \\
\text { (I-J) }\end{array}$} & \multirow[b]{2}{*}{ Std. Error } & \multirow[b]{2}{*}{ Sig. } & \multicolumn{2}{|c|}{$95 \%$ Confidence Interval } \\
\hline & & & & & & Lower Bound & Upper Bound \\
\hline \multirow{12}{*}{ Daily } & \multirow{3}{*}{ KRE } & SSE & -.005196 & .003544 & .542 & -.01510 & .00471 \\
\hline & & HKSE & $-.020209^{*}$ & .003544 & .000 & -.03012 & -.01030 \\
\hline & & TWSE & $-.046418^{*}$ & .003544 & .000 & -.05633 & -.03651 \\
\hline & \multirow{3}{*}{ SSE } & KRE & .005196 & .003544 & .542 & -.00471 & .01510 \\
\hline & & HKSE & $-.015013^{*}$ & .003544 & .000 & -.02492 & -.00511 \\
\hline & & TWSE & $-.041222^{*}$ & .003544 & .000 & -.05113 & -.03131 \\
\hline & \multirow{3}{*}{ HKSE } & KRE & $.020209^{*}$ & .003544 & .000 & .01030 & .03012 \\
\hline & & SSE & $.015013^{*}$ & .003544 & .000 & .00511 & .02492 \\
\hline & & TWSE & $-.026209^{*}$ & .003544 & .000 & -.03612 & -.01630 \\
\hline & \multirow[t]{3}{*}{ TWSE } & KRE & $.046418^{*}$ & .003544 & .000 & .03651 & .05633 \\
\hline & & SSE & $.041222^{*}$ & .003544 & .000 & .03131 & .05113 \\
\hline & & HKSE & $.026209^{*}$ & .003544 & .000 & .01630 & .03612 \\
\hline
\end{tabular}

Based on post-hoc daily test results, as shown in the Table 4, the following 6 conclusions can be drawn:

1) there is no significant difference between $\operatorname{KRE}$ and $\operatorname{SSE}(p>.05)$; 
2) there is significant difference between KRE and HKSE $(p<.001)$;

3) there is significant difference between KRE and TWSE $(p<.001)$;

4) there is significant difference between SSE and HKSE $(p<.001)$,

5) there is significant difference between SSE and TWSE $(p<.001)$;

6) there is significant difference between HKSE and TWSE $(p<.001)$;

Table 4. Post hoc analysis for monthly stock index

\begin{tabular}{|c|c|c|c|c|c|c|c|}
\hline & & SSE & -.005839 & .004127 & .572 & -.01738 & .00570 \\
\hline & KRE & HKSE & $-.020532^{*}$ & .004127 & .000 & -.03207 & -.00899 \\
\hline & & TWSE & $-.157083^{*}$ & .004127 & .000 & -.16862 & -.14554 \\
\hline & & KRE & .005839 & .004127 & .572 & -.00570 & .01738 \\
\hline & SSE & HKSE & $-.014692^{*}$ & .004127 & .005 & -.02623 & -.00315 \\
\hline Monthly & & TWSE & $-.151244^{*}$ & .004127 & .000 & -.16278 & -.13970 \\
\hline & & KRE & $.020532^{*}$ & .004127 & .000 & .00899 & .03207 \\
\hline & HKSE & SSE & $.014692^{*}$ & .004127 & .005 & .00315 & .02623 \\
\hline & & TWSE & $-.136552^{*}$ & .004127 & .000 & -.14809 & -.12501 \\
\hline & & KRE & $.157083^{*}$ & .004127 & .000 & .14554 & .16862 \\
\hline & TWSE & SSE & $.151244^{*}$ & .004127 & .000 & .13970 & .16278 \\
\hline & & HKSE & $.136552^{*}$ & .004127 & .000 & .12501 & .14809 \\
\hline
\end{tabular}

Based on post-hoc monthly test results, as shown in the Table 5, the following 6 conclusions can be drawn:

1) there is no significant difference between $\operatorname{KRE}$ and SSE $(p>.05)$;

2) there is significant difference between $\operatorname{KRE}$ and $\operatorname{HKSE}(p<.001)$;

3) there is significant difference between KRE and TWSE $(p<.001)$;

4) there is significant difference between SSE and HKSE $(p<.001)$,

5) there is significant difference between SSE and TWSE $(p<.001)$;

6) there is significant difference between HKSE and TWSE $(p<.001)$;

Table 5. Post hoc analysis for quarterly stock index

\begin{tabular}{|c|c|c|c|c|c|c|c|}
\hline \multirow{3}{*}{ KRE } & SSE & -.004046 & .004965 & .882 & -.01793 & .00984 \\
\cline { 3 - 8 } & HKSE & $-.077657^{*}$ & .004965 & .000 & -.09154 & -.06377 \\
\cline { 3 - 8 } & TWSE & $.333577^{*}$ & .004965 & .000 & .31969 & .34746 \\
\hline \multirow{2}{*}{ SSE } & KRE & .004046 & .004965 & .882 & -.00984 & .01793 \\
\cline { 3 - 8 } & & HKSE & $-.073611^{*}$ & .004965 & .000 & -.08749 & -.05973 \\
\hline
\end{tabular}




\begin{tabular}{|c|c|c|c|c|c|c|c|}
\hline \multirow{5}{*}{ Quarterly } & TWSE & $.337623^{*}$ & .004965 & .000 & .32374 & .35151 \\
\cline { 2 - 7 } & \multirow{4}{*}{ HKSE } & KRE & $.077657^{*}$ & .004965 & .000 & .06377 & .09154 \\
\cline { 2 - 7 } & SSE & $.073611^{*}$ & .004965 & .000 & .05973 & .08749 \\
\cline { 2 - 7 } & & TWSE & $.411234^{*}$ & .004965 & .000 & .39735 & .42512 \\
\cline { 2 - 7 } & TWSE & KRE & $-.333577^{*}$ & .004965 & .000 & -.34746 & -.31969 \\
\cline { 2 - 7 } & SSE & $-.337623^{*}$ & .004965 & .000 & -.35151 & -.32374 \\
\cline { 2 - 8 } & HKSE & $-.411234^{*}$ & .004965 & .000 & -.42512 & -.39735 \\
\hline
\end{tabular}

Based on post-hoc quarterly test results, as shown in the Table 6 , the following 6 conclusions can be drawn:

1) there is significant difference between KRE and SSE $(p<.001)$;

2) there is significant difference between $\operatorname{KRE}$ and $\operatorname{HKSE}(p<.001)$;

3) there is significant difference between KRE and TWSE $(p<.001)$;

4) there is significant difference between SSE and HKSE $(p<.001)$,

5) there is significant difference between SSE and TWSE $(p<.001)$;

6) there is significant difference between HKSE and TWSE $(p<.001)$;

Table 6. Post hoc analysis for semiannually stock index

\begin{tabular}{|c|c|c|c|c|c|c|c|}
\hline & & SSE & $-.035418^{*}$ & .004654 & .000 & -.04843 & -.02241 \\
\hline & KRE & HKSE & $-.054131^{*}$ & .004654 & .000 & -.06714 & -.04112 \\
\hline & & TWSE & $.856973^{*}$ & .004654 & .000 & .84396 & .86998 \\
\hline & & KRE & $.035418^{*}$ & .004654 & .000 & .02241 & .04843 \\
\hline & SSE & HKSE & $-.018713^{*}$ & .004654 & .001 & -.03172 & -.00570 \\
\hline & & TWSE & $.892391^{*}$ & .004654 & .000 & .87938 & .90540 \\
\hline & HKSE & KRE & $.054131^{*}$ & .004654 & .000 & .04112 & .06714 \\
\hline & & SSE & $.018713^{*}$ & .004654 & .001 & .00570 & .03172 \\
\hline & & TWSE & $.911104^{*}$ & .004654 & .000 & .89809 & .92412 \\
\hline & & KRE & $-.856973^{*}$ & .004654 & .000 & -.86998 & -.84396 \\
\hline & TWSE & SSE & $-.892391^{*}$ & .004654 & .000 & -.90540 & -.87938 \\
\hline & & HKSE & $-.911104^{*}$ & .004654 & .000 & -.92412 & -.89809 \\
\hline
\end{tabular}

Based on post-hoc semiannually test results, as shown in the Table 7, the following 6 conclusions can be drawn:

1) there is significant difference between KRE and SSE $(p<.001)$;

2) there is significant difference between $\operatorname{KRE}$ and $\operatorname{HKSE}(p<.001)$;

3) there is significant difference between KRE and TWSE $(p<.001)$;

4) there is significant difference between SSE and HKSE $(p<.001)$,

5) there is significant difference between SSE and TWSE ( $<.001)$;

6) there is significant difference between HKSE and TWSE $(p<.001)$; 
Table 7. Post hoc analysis for annually stock index

\begin{tabular}{|c|c|c|c|c|c|c|c|}
\hline & & SSE & -.011339 & .010790 & .776 & -.04151 & .01883 \\
\hline & KRE & HKSE & -.034535 & .010790 & .017 & -.06470 & -.00437 \\
\hline & & TWSE & $-1.661983^{*}$ & .010790 & .000 & -1.69215 & $\mid-1.63181$ \\
\hline & & KRE & .011339. & .010790 & .776 & -.01883 & .04151 \\
\hline & SSE & HKSE & -.023196 & .010790 & .202 & -.05336 & .00697 \\
\hline & & TWSE & $-1.650643^{*}$ & .010790 & .000 & -1.68081 & -1.62047 \\
\hline & & KRE & .034535 & .010790 & .017 & .00437 & .06470 \\
\hline Annually & HKSE & SSE & 等. 23196 & .010790 & .202 & -.00697 & .05336 \\
\hline & & TWSE & $-1.627448^{*}$ & .010790 & .000 & -1.65762 & -1.59728 \\
\hline & & KRE & $1.661983^{*}$ & .010790 & .000 & 1.63181 & 1.69215 \\
\hline & TWSE & SSE & $1.650643^{*}$ & .010790 & .000 & 1.62047 & 1.68081 \\
\hline & & HKSE & $1.627448^{*}$ & .010790 & .000 & 1.59728 & 1.65762 \\
\hline
\end{tabular}

Based on post-hoc annually test results, as shown in the Table 8, the following 6 conclusions can be drawn:

1) there is no significant difference between KRE and SSE ( $p>.05$ );

2) there is no significant difference between KRE and $\operatorname{HKSE}(p>.05)$;

3) there is significant difference between KRE and TWSE ( $p<.001)$;

4) there is no significant difference between SSE and HKSE ( $p>.05$ ),

5) there is significant difference between SSE and TWSE $(p<.001)$;

6) there is significant difference between HKSE and TWSE ( $p<.001)$;

\section{Empirical Contributions}

According to the results, it is evident that the market returns are highly diversified among the case stock markets through the investment time horizon. Thus, in order to make the results more visible and applicable, we re-categorise each holding periods into three groups. First is short-term investment period, which includes daily and monthly trading intervals. Second is mid-term investment period, which includes quarterly and semi-annually trading intervals. Third is long-term investment period, which includes annually trading interval (Martin, Maria, Tommy, \& Anders, 2012).

\subsection{Short-Term Investment Period}

According to the results, TWSE appears to be the most profitable market, and the second most profitable market is HKSE. For SSE, returns are mediocre. Investment returns of SSE are better than KRE, however are not as high as HKSE and TWSE. Thus, investors are suggested to be cautious in doing short-term (daily and monthly) investment in KRE.

\subsection{Mid-Term Investment Period}

The best choice for investment in this period appears to be HKSE and then SSE. The middle point market here is KRE. The low return investment market for mid-term investing period 
seems to be TWSE. Thus, investors should be careful with mid-term (quarterly and semi-annually) investment decisions related to TWSE.

\subsection{Long-Term Investment Period}

Based on the findings of this study, investors can expect better long-term investment return from TWSE. There are no significant difference between long-term investment returns of the SSE, HKSE, and KRE. However, fund managers may keep in mind that KRE might be riskier than the HKSE and SSE because of the lowest investment return for the long-term investment period.

\section{Conclusions and Limitations}

\subsection{Conclusions}

This study investigates the differences for diverse holding periods of investments in the case of four Asian stock markets. Thus, the primary objective of this research is to demonstrate that returns of the case stock markets are diversified in different holding periods. To test the proposed hypotheses this study used ANOVA and time series data, with time interval from January 01, 2001 to April 26, 2012. The results of ANOVA indicate that all the presumed hypotheses are supported. Results of post-hoc analysis summarized below.

\subsubsection{Daily (short-term) Trading}

In daily trading, as shown in the Table 3, returns of HKSE, SSE and TWSE are greater than returns KRE. In daily trading, the equity market of Taiwan seems to be the most suitable and the most profitable place than the rest of the markets in this study. Based on the mean values for daily returns of investment the following ranking from best to worst is exhibited: 1) TWSE, 2) HKSE, 3) SSE, and 4) KRE. That is, when considering the average return of all stocks in daily trading the best market seems to be TWSE and the worst market seems to be KRE.

\subsubsection{Monthly (short-term) trading}

In monthly trading, as shown in the Table 4, returns of HKSE, SSE and TWSE are greater than returns KRE. Literally, TWSE seem to be the most suitable and the most profitable place again. Based on the mean values of monthly returns of investment the following ranking from best to worst is displayed: 1) TWSE, 2) HKSE, 3) SSE, and 4) KRE. Considering the average returns of all stocks for the monthly holding period, the TWSE obviously appears outperforming the other three markets while KRE stands at last.

\subsubsection{Quarterly (mid-term) Trading}

In quarterly trading, as shown in the Table 5, returns of HKSE, SSE and KRE are greater than returns TWSE. Interesting turn of events when we move from short-term trading to mid-term trading we can see significant shift in market returns. When it comes to mid-term trading, the TWSE seems to be the least suitable and least profitable place. In fact TWSE shows a loss of capital for quarterly holding period. Based on the mean values for quarterly trading the following rankings from best to worst is presented: 1) HKSE, 2) SSE, 3) KRE, and 4) TWSE. That is, when considering the average return of all stock in quarterly holding period, HKSE 
significantly surpasses all three other markets, while TWSE significantly does the worst.

\subsubsection{Semi-annually (mid-term) Trading}

In semi-annual trading, as shown in the Table 6, likewise quarterly, returns of HKSE, SSE and KRE are greater than returns TWSE. The two mid-term holding periods seem to behave exactly identical with similar significant differences. Thus, the TWSE Taiwan appears to be the least suitable and least profitable place again. Based on the mean values for semi-annual trading the following rankings from best to worst can be assigned: 1) HKSE, 2) SSE, 3) KRE, and 4) TWSE. Therefore, considering the average return of all stock in quarterly holding period, HKSE significantly surpasses all three other markets, while TWSE took the last spot.

\subsubsection{Annual (long-term) Trading}

In annual trading, as shown in the Table 7, returns of HKSE, SSE and TWSE are greater than returns KRE. When it come yearly returns of investment in stock trading, the TWSE seems to come back on top once again to be the most suitable and the most profitable place. Based on the mean values for day trading the following rankings from best to worst can be assigned: 1) TWSE, 2) HKSE, 3) SSE, and 4) KRE. This finding is very similar to that of the short-term trading strategy. That is, when considering the average return of all stocks in yearly holding trading period the best market seems to be the TWSE and the worst market seems to be KRE.

Therefore, we can make a quick and simple conclusion that when it comes to holding stock periods, considering the four markets chosen for this study, long-term and short-term holding periods seem to act similarly. The international traders might think of diversification in the four mentioned markets in order to lower investments risks. Due to the variation of returns between long-term, mid-term and short-term holding periods, investors should shape the best fit strategy to meet the goal of low risk and high profit.

\subsection{Limitations}

This study has several limitations that further studies needed to pay attention. First, due to the availability of data, the present study employs data that covers time period from 2001 to 2012, which is not enough to present the whole period of investment returns of the case stock markets. Although this is the limitation of this study, it should be noted that the economies of the Asian countries have grown much rapidly during the past decade. Therefore studying of the historic data before 2001 may not be helpful to the investors to make future predictions.

Second, this study does not consider specific stocks or specific sectors of stock market. Finally, this study uses ANOVA and post-hoc analysis. Thus, further studies are advised to employ different approaches and use different sources for data than the present study does, to ensure and improve the outcomes.

\section{References}

Abdulkadir, A., \& Green, D. J. (2002). Provincial growth and equality in Indonesia. Paper prepared for 8th Convention of the East Asian Economic Association (4-5 November). Kuala Lumpur. 
Araujo, E. (2009). Macroeconomics shocks and the co-movement of stock returns in Latin America. Emerging Markets Review, 10, 331-344. http://dx.doi.org/10.1016/j.ememar.2009.08.003

Cha, B., \& Cheung, Y. (1998). The impact of the US and the Japanese equity markets on the emerging Asia-Pacific equity markets. Asia-Pacific Financial Markets, 5, 191-209. http://dx.doi.org/10.1023/A:1010038229774

Chiang, T. C., \& Zheng, D. (In Press). An empirical analysis of herd behavior in global stock markets. Journal of Banking \& Finance.

Chow, H. K., Kim, Y., \& Sun, W. (2007). Characterizing exchange rate policy in East Asia: a reconsideration. Journal of Asian Economics, 18, 448-465. http://dx.doi.org/10.1016/j.asieco.2007.02.011

Chuang, I., Lu, J., \& Tswei, K. (2007). Interdependence of international equity variances: evidence from East Asian markets. Emerging Markets Review, 8, 311-327. http://dx.doi.org/10.1016/j.ememar.2007.08.001

Climent, F., \& Meneu, V. (2003). Has 1997 Asian crisis increased information flows between international markets? International Review of Economics and Finance, 12, 111-143. http://dx.doi.org/10.1016/S1059-0560(02)00140-5

De Roon, F. A., Nijman, T. E., \& Werker, B. (2001). Testing for mean-variance spanning with short sales constraints and transaction costs: the case of emerging markets. Journal of Finance, 56, 721-742. http://dx.doi.org/10.1111/0022-1082.00343

Dimson, E., Marsh, P., \& Staunton, M. (2002). Triumph of the Optimists: 101 Years of Global Investment Return. Princeton University Press, Princeton, New Jersey.

Elyasiani, E., Perera, P., \& Puri, T. N. (1998). Interdependence and dynamic linkages between stock markets of Sri Lanka and its trading partners. Journal of Multinational Financial Management, 8, 89-101. http://dx.doi.org/10.1016/S1042-444X(98)00020-6

Goetzmann, W., Li, L., \& Rouwenhorst, K. (2005). Long term global market correlations. Journal of Business, 78, 1-38. http://dx.doi.org/10.1086/426518

Hong Kong Stock Exchange. [Online] Available: http://www.hkex.com.hk/eng/index.htm (February 01, 2013)

Hsiao, F., Hsiao, M., \& Yamashita, A. (2003). The impact of the US economy on the Asia-Pacific region: does it matter? Journal of Asian Economics, 14, 219-241. http://dx.doi.org/10.1016/S1049-0078(03)00018-6

Hung, W., Lu, C., \& Lee, C. F. (2010). Mutual fund herding its impact on stock returns: Evidence from the Taiwan stock market . Pacific-Basin Finance Journal , 18, 477-493. http://dx.doi.org/10.1016/j.pacfin.2010.06.001

In, F., Kim, S., \& Yoon, J. H. (2002). International stock market linkages: evidence from the Asian financial crisis. Journal of Emerging Market Finance, 1, 1-29. 
http://dx.doi.org/10.1016/S1042-4431(98)00029-8

Indrawati, S. (2002). Indonesian economic recovery process and the role of government. Journal of Asian Economics, 13, 577-596. http://dx.doi.org/10.1016/S1049-0078(02)00176-8

Janakiramanan, S., \& Lamba, A. S. (1998). An empirical Examination of Linkages between Pacific Basin Stock Markets. Journal of International Financial Markets, Institutions and Money, 8, 155-173. http://dx.doi.org/10.1016/S1042-4431(98)00029-8

Korean Stock Exchange. [Online] Available: Retrieved from http://eng.krx.co.kr/ (February 01, 2013)

Koshnazarov, S. (2010). LSE Partners with Mongolian Stock Exchange. In E. CAPITAL (Ed.).

Lee, S. (2009). Volatility spillover effects among six Asian countries. Applied Economics Letters, 16, 501-508. http://dx.doi.org/10.1016/S0927-5398(02)00027-0

Li, K., Sarkar, A., \& Wang, Z. (2003). Diversification benefits of emerging markets subject to portfolio constraints. Journal of Empirical Finance, 10, 57-80. http://dx.doi.org/10.1016/S0927-5398(02)00027-0

Lin, J. (2008). Are stock returns on the US used as an exogenous predictor to the Asian emerging equity markets? Applied Economics Letters, 15, 235-237. http://dx.doi.org/10.1080/13504850600706289

Liu, Y., Pan, M., \& Shieh, J. (1998). International transmission of stock price movements: evidence from the U.S. and five Asian- Pacific markets. Journal of Economics and Finance, 22, 59-69. http://dx.doi.org/10.1016/j.socec.2011.12.010

Martin H., Maria A., Tommy G., \& Anders B. ～(2012). Stock investors' preference for short-term vs. long-term bonuses. The Journal of Socio-Economics ～， 41, 137-142. http://dx.doi.org/10.1016/j.socec.2011.12.010

Michael, R. (2009). Charles Darwin on human evolution. Journal of Economic Behavior \& Organization, 71, 10-19. http://dx.doi.org/10.1016/j.jebo.2006.09.005

Mukherjee, P., \& Bose, S. (2008). Does the stock market in India move with Asia? A multivariate cointegration-vector autoregression approach. Emerging Markets Finance and Trade, 44, 5-22. http://dx.doi.org/10.2753/REE1540-496X440501

Pontines, V., \& Siregar, R. (2009). Tranquil and crisis windows, heteroscedasticity, and contagion measurement: MS-VAR application of the DCC procedure. Applied Financial Economics, 19, 745-752. http://dx.doi.org/10.1080/09603100802167239

Return on investment. [Online] Available: Retrieved from http://en.wikipedia.org/wiki/Return_on_investment (February 01, 2013)

Rigobon, R. (2003). On the measurement of the international propagation of shocks: Is the transmission stable? Journal of International Economics, 61, 261-283. http://dx.doi.org/10.1016/S0022-1996(03)00007-2 
Shanghai Stock Exchange. [Online] Available: Retrieved from http://en.wikipedia.org/wiki/Shanghai_Stock_Exchange (February 01, 2013)

Singh, P., Kumar, B., \& Pandey, A. (2010). Price and volatility spillovers across North American, European and Asian stock markets. International Review of Financial Analysis, 19, $55-64$.

Sulloway, F. (2009). Why Darwin rejected intelligent design. Journal of Biosciences, 34, 173-183. http://dx.doi.org/10.1007/s12038-009-0020-8

Syriopoulos, T. (2004). International portfolio diversification to Central European stock $\begin{array}{lllll}\text { markets. } & \text { Applied } & \text { Financial } & \text { Economics, } & 14,\end{array}$ http://dx.doi.org/10.1080/0960310042000280465

Taiwan Stock Exchange. [Online] Available: http://www.twse.com.tw/en/ (February 03, 2013)

Tan, L., Chiang, T., Mason, J., \& Nelling, E. (2008). Herding behavior in Chinese stockmarkets: an examination of A and B shares. Pacific-Basin Finance Journal, 16, 61-77. http://dx.doi.org/10.1016/j.pacfin.2007.04.004

Thomson Reuters Datastream. (2013) Retrieved from: https://forms.thomsonreuters.com/datastream

Zhou, C., Wu, C., \& Yang, L. (2011). The informational role of stock and warrant trades: empirical evidence from China. Emerging Markets Finance and Trade, 47, 78-93. http://dx.doi.org/10.2753/REE1540-496X4701S107 